\title{
A HIGH-PERFORMANCE TEMPERATURE-PROGRAMMED GAS CHROMATOGRAPHY COLUMN
}

\author{
Masoud Agah, Joseph A. Potkay, Andrea L. Elstro, Glambert R. Lambertus, Richard D. Sacks, and Kensall D. Wise \\ Engineering Research Center for Wireless Integrated MicroSystems \\ University of Michigan, Ann Arbor, MI 48109-2101
}

\begin{abstract}
This paper reports the design and fabrication of highperformance Si-glass $\mu \mathrm{GC}$ separation columns having integrated heaters and temperature sensors for temperature programming and integrated pressure sensors for flow control. These $3 \mathrm{~m}$-long $150 \mu \mathrm{m}$-wide $250 \mu \mathrm{m}$-deep columns, integrated on a $3.33 \mathrm{~cm}$ square die, were fabricated using a silicon-on-glass dissolved-wafer process. The $2000 \mathrm{ppm} /{ }^{\circ} \mathrm{C}$ TCR of the temperature sensors and the $52 \mathrm{fF} / \mathrm{kPa}$ sensitivity of the pressure sensors satisfy the requirements needed to achieve reproducible separations in a $\mu \mathrm{GC}$ system. Using these columns, highly-resolved twenty-component separations were obtained with analysis times a factor of two faster than the isothermal responses.
\end{abstract}

\section{INTRODUCTION}

Gas chromatography (GC) systems are instruments that separate the different components of a gaseous mixture in space and time $[1,2]$. In a GC system, a gas sample is vaporized and injected into a separation column that has been coated with a stationary phase. Different gaseous molecules spend different amounts of time in the stationary phase coating while traversing the column so that they emerge from it separated in time. The gases then pass over a detector, generating an electrical output signal proportional to the concentration of the compound. The delay through the column identifies the species present [1-3].

Conventional GCs tend to be large, fragile, and relatively expensive table-top instruments with high power consumption, but they are known to deliver accurate and selective analysis. Microsystems based on chromatography are a promising approach to gas analysis and are rapidly moving toward small portable microinstruments. Such systems will make gas chromatography a pervasive method of gas analysis, with applications in homeland security, monitoring food freshness, industrial process control, and improving environment quality [2]. They promise to actually increase performance while drastically decreasing size and cost.

The basic - and heart - of a $\mu \mathrm{GC}$ system is its separation column. There have been many efforts to miniaturize such columns (along with the rest of the instrument) [1-6]; however, column development faces difficult challenges in minimizing power and in implementing the complex temperature and pressure control needed to enhance performance. Temperature programming can be used to separate samples over a broad boiling range and reduces the analysis time [2, 7]. Pressure control is also required to achieve reproducible separations since variations in the flow rate affect the retention times [8].

This paper reports the first high-performance $\mu \mathrm{GC}$ separation columns having integrated heaters and temperature sensors for temperature programming as well as integrated pressure sensors for flow control. These columns are part of a $\mu \mathrm{GC}$ intended for an environmental monitoring system currently under development as part of the National Science Foundation Engineering Center for
Wireless Integrated Microsystems. The following sections describe the theory, fabrication, and experimental results for these microfabricated columns.

\section{THEORETICAL DISCUSSION}

A common way to express the performance of GC columns is to determine the number of theoretical plates $(N)$ as well as the height-equivalent-to-a-theoretical-plate (HETP). A theoretical plate is a discrete section in which a solute molecule equilibrates between the stationary and mobile phases. For square channels, HETP is given by [1]:

$$
H E T P=2 \frac{D_{g}}{u}+\frac{1+9 k+\frac{51}{2} k^{2}}{105(1+k)^{2}} \frac{u w^{2}}{D_{g}}+\frac{8 h^{2} k u}{3 D_{l}(1+k)^{2}}
$$

where $D_{g}$ and $D_{l}$ are the diffusion coefficients in the gas and liquid phases, respectively, $k$ is the retention factor, $h$ is the thickness of the liquid phase, and $w$ is the channel width. To determine the total resolving power of a column, the total number of plates, $N$, is calculated as:

$$
N=\frac{L}{H E T P}
$$

where $L$ is the column length.

Analysis time is also a key factor in determining the quality of chemical analyzers, especially when it comes to near real-time applications. In a GC system, a gas mixture is separated as its components distribute between mobile and stationary phases over time. All components spend the same time in the mobile phase, equal to the unretained peak time, given by:

$$
t_{m}=\frac{L}{\bar{u}}
$$

where $\bar{u}$ is the average carrier gas velocity. Retention time $\left(t_{r}\right)$ is the time spent by a compound in both phases. The adjusted retention time considers only the time spent in the stationary phase:

$$
t_{r}^{\prime}=t_{r}-t_{m}
$$

and finally, the retention factor or capacity factor of a solute is defined as:

$$
k=t_{r}^{\prime} / t_{m}
$$

The capacity factor is specific for a given compound and is constant under constant conditions [9].

Column temperature has a significant influence on component retention and separation. At a given temperature, the elution order of compounds will not depend on other GC conditions. However, in a temperature programming scenario, 
analytes may change their relative positions as the temperature changes while they pass through the column [9]. Temperature programming will cause a continuous, monotonic change in the retention factor for each analyte $[\mathbf{9 - 1 1}]$ :

$$
\ln k=A+\frac{B}{T}
$$

where $A$ and $B$ are empirical constants and $T$ is the temperature. Increasing the temperature reduces the retention factor and hence decreases the analysis time.

It is shown explicitly in [11] that an isothermal GC in comparison to a temperature-programmed GC provides the highest separation capacity but at the expense of noticeably longer analysis time. Using longer columns in a temperature-programmed GC compensates for its disadvantage in separation capacity while still retaining considerably shorter analysis time. It is important to note that raising the column temperature reduces the carrier gas viscosity and hence for a constant inlet pressure, the flow rate decreases. Therefore, flow control is required to maintain a constant flow rate during analysis in order to prevent variations of retention times and degradation of the separation efficiency [8].

For the columns utilized in the WIMS ERC $\mu \mathrm{GC}, 30-110^{\circ} \mathrm{C}$ and $40^{\circ} \mathrm{C} / \mathrm{min}$ are selected as the targets for the column temperature range and temperature programming rate, respectively, so as to separate 30 volatile organic compounds in less than $10 \mathrm{~min}$. Also, the depth, width and length of the Si-glass columns are $250 \mu \mathrm{m}, 150 \mu \mathrm{m}$, and $3 \mathrm{~m}$, respectively, representing a trade-off among the analysis time, HETP, and volumetric flow rate. Moreover, air - instead of hydrogen and helium - is used as the carrier gas to eliminate the need for gas storage and to allow further miniaturization [1].

\section{FABRICATION}

The fabrication is based on a silicon-on-glass dissolvedwafer process. First, recessed areas are created in the silicon to form the cavities and flow tunnel for the pressure sensors and the lead tunnel for the glass electrodes. Then, a $1.2 \mu \mathrm{m}$-thick thermal oxide is grown to protect the cavities during a deep boron diffusion (Fig. 1a). Using patterned PR9260 as a mask, DRIE is used to etch the silicon to form rectangular microchannels in a $3.33 \mathrm{~cm}$ square area and reduce the thermal mass of the silicon rim. After stripping the resist, highly boron-doped etch-stops are diffused into the channel area (Fig. 1b), followed by a $4 \mu \mathrm{m}$-shallow boron diffusion to form the sensor membranes. Then, a $2000 \AA$ oxide is grown on the back as an electrical isolation layer and subsequently $250 / 500 \AA$ of $\mathrm{Ti} / \mathrm{Pt}$ is evaporated and patterned using lift-off to form the heaters and temperature sensors. A $3000 \AA$-thick LTO deposition on both sides of the wafer is used to stress-compensate the tensile $\mathrm{p}++$ diaphragm [12] and anneal the temperature sensors. The LTO thickness on the front should not exceed the aforementioned value, otherwise it will degrade the anodic bonding performance [13]. A $1 \mu \mathrm{m}$-thick LTO layer is deposited on the back side to serve as a mask in EDP (Fig. 1c). Bottom electrodes and metal interconnects for the pressure sensors are patterned onto the glass wafer with an evaporated $\mathrm{Ti} / \mathrm{Pt} / \mathrm{Au}$ stack. Then, the wafers are anodically bonded to seal the channel at $400^{\circ} \mathrm{C}, 1000 \mathrm{~V}$, and $200 \mathrm{~N}$ of pressure. Next, the back oxide is patterned to open EDP etch windows and contact areas for the heaters, temperature sensors, and the bulk. $\mathrm{Cr} / \mathrm{Au}$ is then sputtered and patterned on the back of the silicon substrate to form metal interconnects and cover the silicon rim for heat distribution (Fig. 1d). After that, the glass wafer is thinned in HF for $45 \mathrm{~min}$ to reduce the thermal mass. It should be noted that a support wafer is (a)

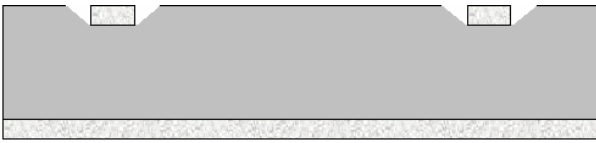

(b)

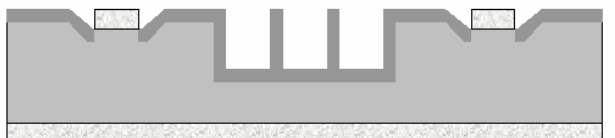

(c)

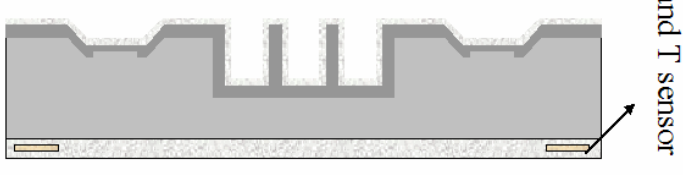

(d)

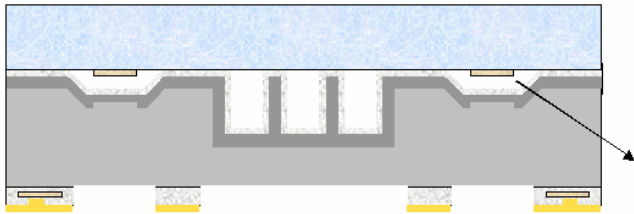

(e)

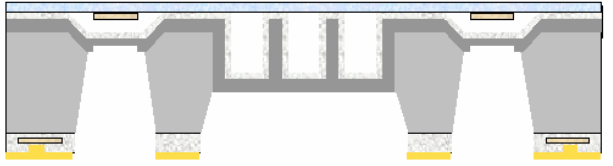

Figure 1. Silicon-on-glass dissolved wafer process flow.

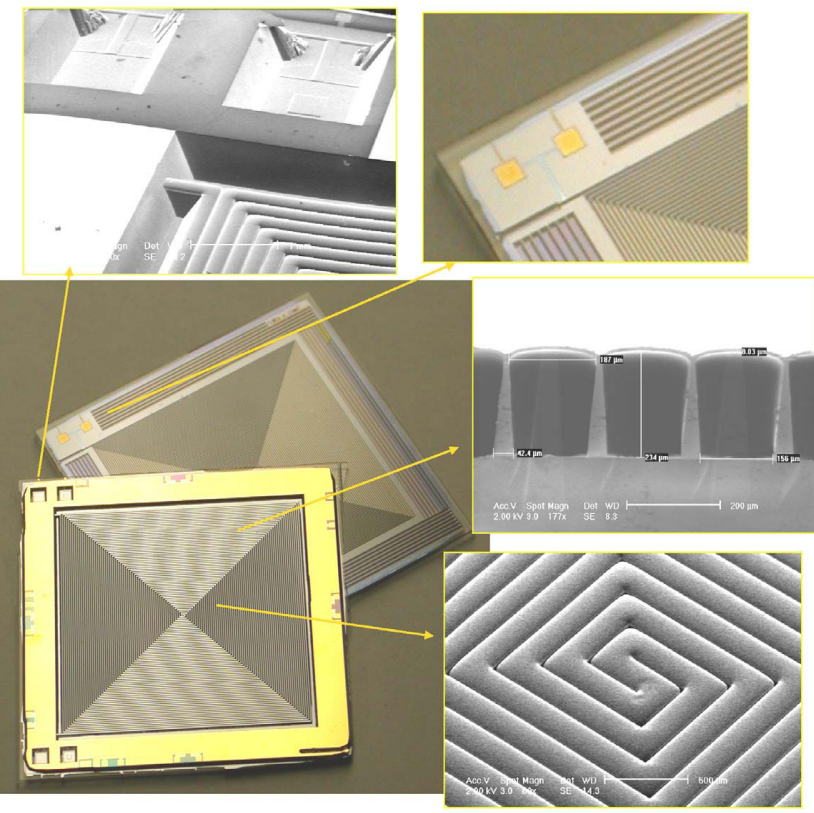

Figure 2. Center left: Top and bottom views of the fabricated separation column. Clockwise from top left: (1) SEM image of the column entry and the pressure sensors, (2) the pressure sensor electrodes, the column entry and the silicon rim that is etched to reduce the thermal mass, (3) cross-sectional view of a non-thinned etched-back column, and (4) SEM image of the column back.

temporarily attached to the back side to protect it during this long etch. In addition, the solution is stirred to obtain a smooth surface. This step thins the glass to less than $80 \mu \mathrm{m}$. Following glass thinning, EDP is employed to etch back the column and release the pressure sensors (Fig. 9e). With the columns fabricated, fused silica capillaries are attached to the side ports for fluidic 
interconnects, and the columns are coated with polydimethylsiloxane, a non-polar stationary phase.

Fig. 2 shows the fabricated etched-back column. Each column port has its own pressure sensor; consequently, measurements of pressure differences are independent of ambient fluctuations and the column temperature. The SEM photo of the pressure sensors displays a device without the gold ring, causing significant undercut. As seen in Fig. 2, the silicon rim has been selectively etched to reduce the thermal mass. Different temperature sensors were also defined on the die to explore the thermal behavior of the column at various points. Moreover, one heater was integrated on each side of the die to suppress temperature gradients around the heaters and reduce temperature non-uniformity of the column during transients [2].

\section{THERMAL BEHAVIOR}

Details of the steady-state power requirements of the Si-glass simple columns are discussed in [2]. The thermal behavior of the etched-back columns is similar to those of simple columns listed in Table 1 except for their transient response. Analogous to its electrical counterpart, the thermal time constant can be estimated as:

$$
t_{t h}=R_{t h} \times C_{t h}
$$

where $R_{t h}$ and $C_{t h}$ are the effective thermal resistance and capacitance of the system. Thermal resistance and power consumption $\left(P_{s s}\right)$ are related as:

$$
P_{s s}=\frac{\Delta T}{R_{t h}}
$$

where $\Delta T$ denotes the temperature rise of the column. To lower the power consumption, the thermal resistance should be increased by isolating the column from its surrounding environment, using standoffs and vacuum packaging to reduce both convective and conductive losses and covering the column surface with a low emissivity material such as gold to shrink radiative losses [2].

The thermal capacitance is given by:

$$
C_{t h}=\sum C_{t h, i}=\sum_{i} m_{i} \widetilde{C}_{i}
$$

where $m$ and $\widetilde{C}$ are the mass and the specific heat of each component of the column, respectively. For the same input power, the etched-back columns show a similar steady-state temperature but a much higher heating rate due to their lower thermal mass. To obtain a temperature ramp of $40^{\circ} \mathrm{C} / \mathrm{min}$ with a final temperature of $100^{\circ} \mathrm{C}$ under the vacuum conditions listed in Table 1 , the power source should deliver $1.2 \mathrm{~W}$ and $600 \mathrm{~mW}$ for a simple and etchedback columns, respectively, during transients. Although the cool-

Table 1. Required sustained power for $T_{\text {column }}=100^{\circ} \mathrm{C}[2]$.

\begin{tabular}{||l|l|c||}
\hline \multirow{2}{*}{$\begin{array}{l}\text { Directly on PCB @ } \\
\text { atmospheric pressure }\end{array}$} & Free space & $4.4 \mathrm{~W}$ \\
\cline { 2 - 3 } & $7.5 \mathrm{~mm}$-high package & $3.4 \mathrm{~W}$ \\
\hline \hline \multirow{2}{*}{$\begin{array}{l}\text { Standoffs, gold } \\
\text { protection, and metal } \\
\text { package }\end{array}$} & Atmospheric pressure & $650 \mathrm{~mW}$ \\
\cline { 2 - 3 } & Vacuum & $100 \mathrm{~mW}$ \\
\hline
\end{tabular}

down of the etched-back columns is also faster due to the lower mass, for the $3 \mathrm{~m}$-long silicon-glass columns, this thermal time constant is still very significant. For columns having a thermal capacitance of $0.7 \mathrm{~J} /{ }^{\circ} \mathrm{C}$, the thermal time constant in vacuum at $100 \mathrm{~mW}$ of steady-state power consumption is still about $9 \mathrm{~min}$.

\section{SERPARATION PERFORMANCE}

The temperature sensors integrated with these columns have TCRs of $2000 \mathrm{ppm} /{ }^{\circ} \mathrm{C}$, sufficient to allow column temperature to be controlled to $<0.5^{\circ} \mathrm{C}$. The pressure sensors should be operated in the vicinity of the flow rate where the HETP is minimized. It has been found experimentally that the maximum separation efficiency is obtained with a flow velocity of $\sim 10 \mathrm{~cm} / \mathrm{s}$, corresponding to a pressure drop of $5-10 \mathrm{kPa}$ across the $3 \mathrm{~m}$ column. Around this point, the pressure sensors have a sensitivity of $52 \mathrm{fF} / \mathrm{kPa}$, allowing adequate flow control to ensure reproducible separations. The burst pressure of the columns is above 50 psi.

With the sensors calibrated, different experiments were conducted to explore the separation capabilities of the columns. The chromatograms used air as the carrier gas and a commercial flame-ionization detector. Experimentally, the number of plates can be calculated as $[\mathbf{1}]$ :

$$
N=5.545\left(\frac{t_{R}}{w_{1 / 2}}\right)^{2}
$$

where $w_{1 / 2}$ is the width of the peak at half height. The numbers of plates were calculated using an isothermal separation and were found to be approximately 8000 . This is significantly higher than the previously reported value of 4900 [1] due to improvements in the coating techniques for the $\mu \mathrm{GC}$ columns.

Fig. 3a displays the separation of 20 compounds obtained at room temperature. While the first five compounds are separated in about one minute, it takes about $10 \mathrm{~min}$ for chlorobenzene - which has a high boiling point $\left(132^{\circ} \mathrm{C}\right)-$ to elute from the column. Fig. $3 \mathrm{~b}$ shows a separation of the same mixture with the column run at $30^{\circ} \mathrm{C}$ for $1 \mathrm{~min}$ followed by a temperature ramp of $5^{\circ} \mathrm{C} / \mathrm{min}$ for $5 \mathrm{~min}$. Although less effective for low boiling compounds, this temperature program has reduced the analysis time for chlorobenzene by a factor of two. Using higher programming rates decreases the retention time more effectively but at the cost of resolution.

\section{CONCLUSION}

This paper has reported silicon-glass $\mu \mathrm{GC}$ columns having integrated heaters and temperature sensors for temperature programming as well as pressure sensors for flow control. Twenty compounds are separated in less than $6 \mathrm{~min}$. The $2000 \mathrm{ppm} /{ }^{\circ} \mathrm{C}$ TCR of the temperature sensors and the $52 \mathrm{fF} / \mathrm{kPa}$ sensitivity of the pressure sensors are sufficient to achieve reproducible separations in a $\mu \mathrm{GC}$ system. The thermal time constant and transient power requirements of these columns are half of those of their predecessors [2].

\section{ACKNOWLEDGMENTS}

This work was supported primarily by the Engineering Research Centers Program of the National Science Foundation under Award Number EEC-9986866. Travel support has been generously provided by the Transducers Research Foundation and by the DARPA MEMS and DARPA BioFlips programs. 

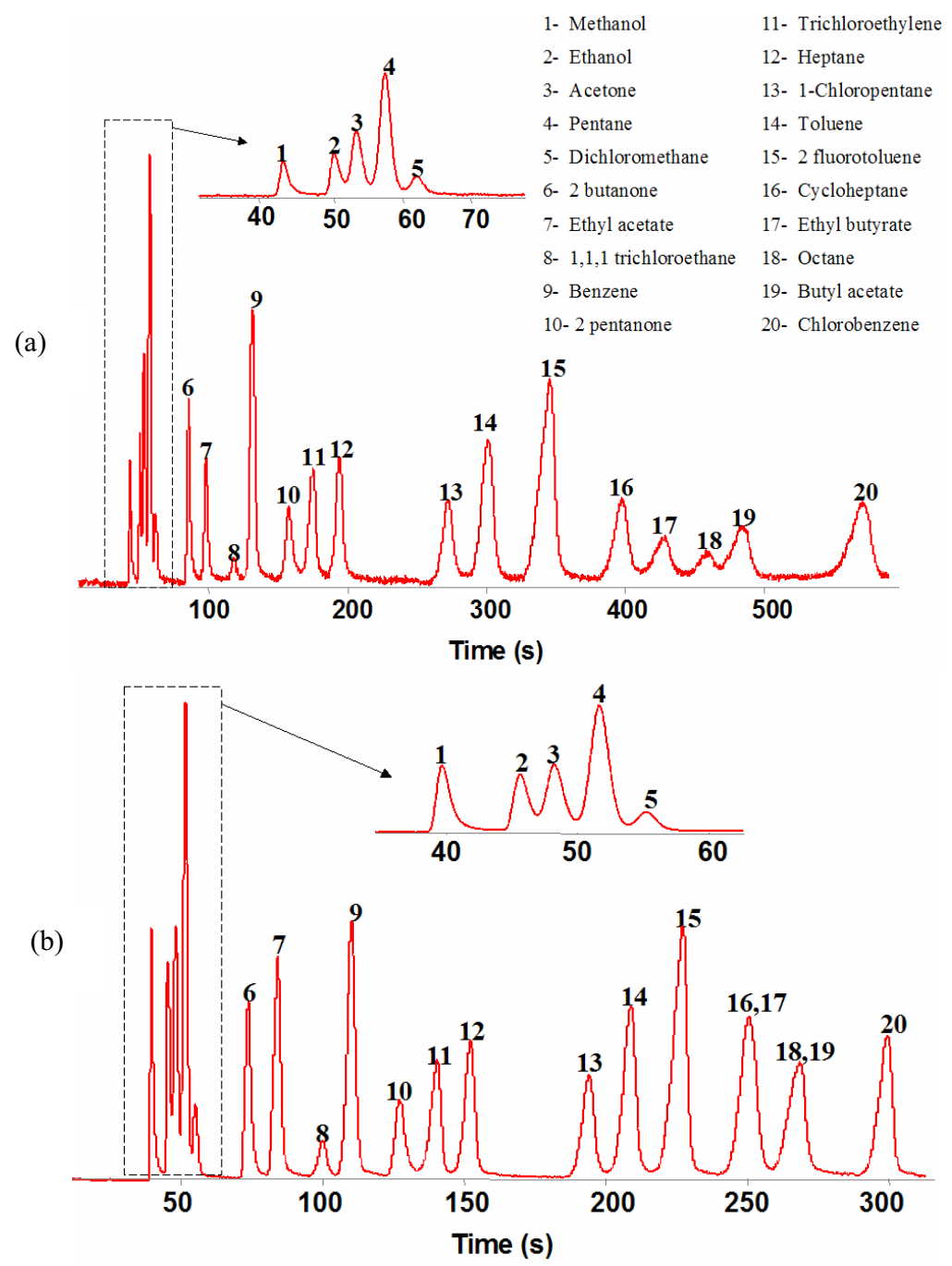

Figure 3. Chromatograms achieved using the $3 \mathrm{~m}$ column. Air is used as the carrier gas: (a) isothermal run at room temperature, (b) isothermal run at $30^{\circ} \mathrm{C}$ for 1 min followed by temperature programming for 5 min with a rate of $5^{\circ} \mathrm{C} / \mathrm{min}$.

\section{REFERENCES}

1. J. A. Potkay, J. A. Driscoll, M. Agah, R. D. Sacks, and K. D. Wise, "A High-Performance Microfabricated Gas Chromatography Column," IEEE MEMS Conf., pp. 395-398, 2003.

2. M. Agah, J. A. Potkay, J. A. Driscoll, R. D. Sacks, M. Kaviany, and K. D. Wise, "Thermal Behavior of High-Performance Temperature-Programmed Microfabricated Gas Chromatography Columns," IEEE Int. Conf. on Solid-State Sensors, Actuators and Microsystems, Boston, pp. 1339-1342, June 2003.

3. E. S. Kolsear and R. R. Reston, "Review and Summary of a Silicon Micromachined Gas Chromatography System," IEEE Trans. Components, Packaging, and Manufacturing Technology, 66, pp. 481-486, 1998.

4. H. Noh, P. J. Hesketh, and G. D. Frye-Mason, "Parylene Gas Chromatographic Column for Rapid Thermal Cycling," IEEE J. of Micoelectromech. Syst., 11, pp. 718-725, 2002.

5. R. W. Tjerkstra, M. de Boer, E. Berenschot, J. G. E. Gardeniers, A. van den Berg, and M. C. Elwenspoek, "Etching Technology for Chromatography Microchannels," Electrochimica Acta, $\underline{42}$, pp. 3399-3406, 1997.

6. E. B. Overton, H. P. Dharmasena, U. Ehrmann, and K. R. Carney, "Trends and Advances in Portable Analytical Instrumentation," Field Analytical Chemistry and Technology, 1, pp. 87-92, 1996.
7. H. M. McNair and G. L. Reed, "Fast Gas Chromatography: The Effect of Fast Temperature Programming," J. of Microcolumn Separation, 12, pp. 351-355, 2000 .

8. F. R. Gonzalez and A. M. Nardillo, "Theoretical and Practical Aspects of Flow Control in Programmed-Temperature Gas Chromatography," J. of Chromatography A, 757, pp. 97-107, 1997.

9. R. Ong, P. Marriott, P. Morrison, and P. Haglund, "Influence of Chromatographic Conditions on Separation in Comprehensive Gas Chromatography," J. of Chromatography A, 962, pp. 135$152,2002$.

10. L. M. Blumberg and M. S. Klee, "Elution Parameters in Constant-Pressure, Single-Ramp Temperature-Programmed Gas Chromatography," J. of Chromatography A, 918, pp. 113-120, 2001.

11. L. M. Blumberg and M. S. Klee, "Quantitative Comparison of Performance of Isothermal and Temperature-Programmed Gas Chromatography," J. of Chromatography A, 933, pp. 13-26, 2001.

12. A. DeHennis and K. D. Wise, "A Double-Sided Single-Chip Wireless Pressure Sensor," IEEE MEMS Conf., pp. 252-255, 2002.

13. J. A. Plaza, J. Esteve, and E. Lora-Tamayo, "Effect of Silicon Oxide, Silicon Nitride and Polysilicon Layers on the Electrostatic Pressure during Anodic Bonding," Sensors and Actuators A, 67, pp. 181-184, 1998. 